\section{Research on research}

The UK Social Research Council (SSRC) has approved a grant application from the Science Policy Research Unit (SPRU) of the University of Sussex to assess the criteria used by the Science Research Council (SRC) for capital projects in basic science. Chris Sherwell reports.

IT WAS perhaps inevitable. Certainly an investigation of the funding of big science in Britain had everything going for it. Hard economic times produce whipping boys, and in Britain's research community it is big science. Likewise growing disciplines generate new fields to conquer, and for the social sciences in Britain science policy is indisputably one of them. Last week's news that the SSRC is funding research on the SRC's funding of research should therefore have been no surprise; in fact the fall-out may be more than inconsequential.

No one is denying that the SSRC has the right and duty to sponsor policy research. And no one doubts the SRC is a good candidate for consideration in the field of science. It takes a major $(54 \%)$ but now declining share of the £216-million science budget doled out to the research councils. Similarly, with high energy physics, astronomy, space and radio science-the traditional areas involving large capital-spending projects-consuming some $60 \%$ of that share, big science is a natural object of attention. Indeed, in annual spending terms it is comparable to research and development on the fast breeder reactor or, in its day, on Concorde.

But there are some raised eyebrows, both inside and outside the SRC. Scientists who privately frown on some of the projects sponsored by the SSRC are never too difficult to find, of course; and the SRC cannot comment officially on projects sponsored by other research councils. But some reactions last week were sceptical. The director of one big science laboratory said rather obviously that he would have preferred to see the money going to his own work. Others, however, doubt the motives behind the proposed research. There were also questions about whether the project could even be done.

The proposal, a year in gestation, is contained in a document running to 18 pages with 5 appendices. It was submitted by Dr Roy Turner and Mr Keith Pavitt of SPRU and Dr Norman Dombey, reader in theoretical physics at Sussex, to the SSRC's political science committee. The SSRC approved the grant application in principle almost three weeks ago. The amount involved is $£ 26,345$ over two years, and the team is now looking urgently for a scientist and a social scientist so that the work can begin in October.

Their case for the study is simple. There is not as much work in Britain on the problems of science policy as there ought to be compared with North America. The SRC disposes of a large sum of money on basic research, and now faces hard choices distributing resources between big science and the rest of science. Yet, says the team, it is not known whether there is any technological benefit from, say, a high energy physics programme which could not have been achieved more cheaply by direct industrial research; nor are there guidelines on what proportions of funds should be allocated to fields in which there will be no foreseeable technological benefit.

The team says it has four aims. The first is to assess the research of six SRC centres in terms of certain criteria. The six centres are in high energy physics (CERN, Rutherford and Dares- bury) and in astronomy (the Isaac Newton telescope, the Nuffield radio astronomy laboratories and the Mullard radio astronomy observatory). The criteria are 'intrinsic' (by which is meant the merit of the science and the researchers, and the benefits to other fields of science); 'educational' (the benefit to those who teach and those who work in other scientific fields); and 'technological' (the long term and short term application of the results and methods of research).

The team expects to spend twothirds of its time on this aspect alone. The rest will be spent comparing the actual performance of the centres with their original justification, applying what is learned to proposals to set up new centres (the team has in mind the high powered laser facility and, though it is not in the SRC's remit, JET, the European fusion project), and finally considering British and international practice in funding big science.

In its proposal the team explains how it plans to proceed, and it is here that the difficulties may emerge. They will assess the research by speaking to scientists in the field, circulating questionnaires and examining published papers. The original justification for the centres will be

\section{Bondi goes to Energy}

As WIDEly expected, Sir Hermann Bondi is to replace Dr Walter Marshall as Chief Scientist in the UK Department of Energy. For the past six years Sir Hermann has been Chief Scientific Adviser at the Ministry of Defence. He goes into the Department of Energy with no strongly expressed views on the record concerning choice of reactor, the balance between nuclear, hydrocarbon and renewable energy sources, or the wisdom of a fastbreeder programme; he freely admits that he has a lot to learn.

Sir Hermann looks back on his time at the Ministry of Defence with satisfaction; in part his role has been as a person to whom anyone could turn for disinterested and friendly advice and criticism. But he has always preached mobility-sometimes to a rather hostile audience within the civil service-and he clearly practises what he preaches. In his own words, the defence post is the "fourth good job I have thrown up". The others were a lectureship and fellowship at Cambridge, a professorship at Kings
Sorry, for copyright reasons some images on this page may not be available online

College, London, and the directorship of the European Space Research Organisation. He admits there is a touch of masochism in this, but he felt he was getting too comfortable at Defence and was no longer an outsider. It will be interesting to see whether the Ministry of Defence has the courage to appoint another outsider. 
learned, the team says, by interviewing those involved in the decisions (like Sir Alec Merrison and Sir Denys Wilkinson in the case of Rutherford and Daresbury and Sir Martin Ryle in the case of Mullard), from published sources (in the case of CERN) and if possible through access to original documents.

But the team is likely to face a critical problem over access to SRC documents. When Mike Gibbons and John Hartland did their study of CERN for the old Council of Scientific Policy (CSP) -a study the team mentions-the SRC gave special dispensation because the study was confidential to the Council; when Margaret Gowing sought SRC documents for her study of CERN on behalf of CERN, the SRC was prepared to allow access but the Department of Education and Science refused under the thirty-year rule. On that history, access is likely to be denied to the SPRU researchers.

The team does not see possible denial of access as a special difficulty. But Gibbons thinks otherwise. Not only did it take him and Hartland two years to do their study, which was of one centre, not six plus two new ones; they also found the original documents essential in providing what he calls a "well constructed net", the holes of which could be plugged with the help of interviews. Only with the documents could they appreciate just how much memories failed with time and how beneficial hindsight could be.

Whether or not the research yields controversial findings, the fact that it is going ahead at all has certainly provoked interest. The SSRC has some $£ 25,000$ at its disposal for science policy studies; this used to be in the hands of the CSP but was transferred to the SSRC when the Advisory Board for the Research Councils (ABRC) began. This award to the SPRU team means that other applications are denied. That is nothing new, except that, in going to one large project, it is ironically favouring 'big science policy' proposals at the expense of others whose merit may be as clear. More interestingly, and particularly as the research is about the SRC, the SRC is certain to have seen a copy of the proposals at an early stage and to have passed a verdict on it.

Two factors indicate why the SRC might be unhappy about it. One is the precedent of the Gowing case: lack of access is bound to reduce the value of the research. The other is its natural misgivings about the quality and partiality of science policy research, using anecdotal evidence or not. Indeed, Norman Dombey's own article on CERN, in The Times Higher Education Supplement earlier this year, is unlikely to have endeared this project to the SRC. And Keith Pavitt's views on the use to which Britain's scientists and engineers are put (typically, into aircraft, nuclear reactors and weapons instead of motor cars and machinery) won't have helped.

The topicality of the subject may have assisted the SSRC in reaching a decision. But one suggestion being put about last week, which could not be confirmed, was that the SSRC's political science committee regards its support for the SPRU proposal as a test case in its efforts to establish itself as the body sponsoring research that monitors decisions in government. The project, it was suggested, is a useful addition to the pressure for a lifting of the thirty-year rule.

As far as Dr Saul Rose, the committee's chairman, is concerned, there are bound to be differing views of its support for the project, as there are for much of the work it sponsors. As for projects that could "come up against a stone wall" because of lack of access, it was always hoped that something could be worked out; in any case projects were monitored, and could be called off or perhaps reshaped if they were unlikely to achieve the intended aims.

In the end, though, the project will be judged by its results. No one wanted to anticipate those last week, or to predict their likely impact. But one former high energy physicist privately expressed his reservations. The big science community in Britain, he said, was now highly sensitive to criticism after the financial battering of recent years. Though prepared to admit that the findings might be interesting, he couldn't see what useful purpose the project would ultimately serve.

\section{Reactor choice: last lap looms}

THE final and most important phase of Britain's tortuous debate over which type of thermal nuclear reactor should follow the existing Magnox generation is just beginning. Last week the Department of Energy (DEN) published extracts from the assessment made over the past nine months by the National Nuclear Corporation (NNC) of the three thermal reactor systems under scrutinythe Pressurised Water Reactor (PWR), the Advanced Gas-Cooled Reactor (AGR) and the Steam Generating Heavy Water Reactor (SGHWR).

At the same time the Health and Safety Executive published an account from its Nuclear Installations Inspectorate (NII), responsible for nuclear safety, of its study of the generic safety issues of PWRs. And the DEN also made available a summary of the discussions on nuclear energy policy which emerged at the closed weekend seminar it held in May.

The nuclear industry, the customers the politicians and others are expected to digest the contents of the massive NNC and NII volumes during a quiet August; discussions in September may then allow the matter to be put before the Cabinet for collective decision sometime in October. Mr Anthony Wedgwood Benn, the Secretary of State for Energy, for one, is looking forward to an interesting debate.

The NNC report says a decision has to be taken now both about the reactor systems and about actual orders "if the nuclear power option is to be maintained in a meaningful way". It says categorically that "there is no case for the adoption of the SGHWR" because there could be no operational experience of commercial sizes for a decade, there is no chance of exports and it is the most costly of the three.

Over the PWR and AGR, the report offers three options: continue with AGR, do not adopt PWR; adopt PWR, finish the current AGR programme but don't add to it; and adopt PWR, continue with AGR. The NNC says it cannot advise the first course because it would be rejecting important export opportunities; to be grasped, moreover. these require a decision now. The second course, it says, would help exports and lead to "the cheapest available electric power for Britain", but construction of the first PWR could only start in 1980; for the course to be acceptable, ways must be found of "maintaining the confidence and enthusiasm" of those laid off by the lack of AGR work.

The third course offers the advantage of keeping open an option, but has the disadvantage of dividing available resources. "In practice", the report suggests, "it is not likely to be sensible to maintain an ordering programme for two systems beyond the early 1980s". The summary concludes that the early adoption of the PWR would have to be supported by a domestic ordering programme of more than one reactor, and that an AGR station would have to be ordered and built, if the purposes of the choice are to be achieved.

The choice of thermal reactor was also the subject of a session at the nuclear policy seminar. Although Sir Alan Cottrell, former government science adviser, disagreed, both Ned Franklin of the NNC and Walter Marshall, the DEN's former chief scientist, thought safety arguments were not a significant factor in the choice, a point borne out by the NII report, which concludes that "there is no fundamental reason for regarding safety as an obstacle" to choosing the PWR.

One interesting contribution to the seminar came from Sir Hermann Bondi, however, whose appointment to the DEN's as chief scientist was confirmed last week. It was very likely, he said, that the first major acoident would be with a PWR because of their widespread adoption; there could be some advantage he said, in being outside the main stream. As in the NNC report, the seminar summary also reveals clearly the importance attached to the matter of exports in reaching a decision.

Chris Sherwell 